\title{
A Study on the Quality of Life Improvement in Fixed IoT Environments: Utilizing Active Aging Biomarkers and Big Data
}

DOI: 10.12776/QIP.V21I2.883

\author{
Eul Hee Roh, Sang Chan Park \\ Received: 15 February 2017 Accepted: 19 April 2017 Published: 31 July 2017
}

\begin{abstract}
Purpose: Aim of this study is to suggest a framework that can measure and assess Quality of Life (QoL) of elderly people objectively, by measuring their active aging status through biomarker sensors under a Fixed Internet of Things (IoT) and Building Information Modeling (BIM) technology environment.

Methodology/Approach: An objective QoL measurement \& assessment framework that can replace previous subjective QoL measurements.

Findings: In this study, we mapped and suggested the active aging measures and corresponding biomarker sensors to derive an objective Healthcare Related Quality of Life (HRQOL) composite index so that we can replace HRQOL subjective question value. We also configured an environment to objectively measure, transfer, and store biomarker sensor values using Fixed IoT and BIM.

Research Limitation/implication: We conducted a preliminary study on establishing the relationship between the existing HRQOL survey and activeaging biomarker measurements. Moreover, the research subjects were limited to being individual elderly residents of a nursing home.

Originality/Value of paper: This study is meaningful in that it suggests a method of replacing the conventional QoL survey with objective QoL measurements through IoT sensors. Furthermore, we consider the surrounding living environment that might greatly affect the QoL of individuals.
\end{abstract}

Category: Research paper

Keywords: QoL; active aging; biomarker; fixed IoT; BIM 


\section{INTRODUCTION}

Studies of QoL (Quality of Life) share a commonality in measuring subjects. When measuring subject's health status improvement level, most surveys ask about the number of days a subject suffered pains from specific health problems. The intrinsic weakness of this type of QoL survey question is that it can't exclude the subjectivity of responses. To overcome this weakness, we need objective measurements that utilize various sensors. In our QoL measurements, the focus of the suggested approach changes from illness to wellness. Wellness approaches suggests a new QoL scale that focuses on measuring a subject's activeness. Moreover, measuring methods that utilize sensors extend not only individual subject's health status measurements, but can also reflect improved levels in group QoL. In order to improve a specific individual's QoL level, knowledge on the interactive behaviours of the group that they belong to is also important.

The emergence of wellness approaches, managing general lifestyles to improve an individual's QoL, lead to the term 'active aging' along with the advent of aging societies. Active aging is a concept that promotes the maintenance of a physical, cognitive, and emotional health status of the elder persons, thus allows them for continuous, active participation in daily and social life into old age (WHO, 2002).

To realize goals of the active aging, we should consider the use of biomarkers for measuring general aging status. These biomarkers measure the status of a subject's organs including heart, lungs, kidneys, muscles, nerves, bones, hormones and skin. Many active aging biomarkers rely on sensor measurements.

As previously mentioned sensors for measuring QoL are an integral part of IoT (Internet of Things), a combination of IoT and QoL is realized. In the past, we have used temporary mobile sensors by physically attaching them directly to subjects when we wanted to measure their health status.

In addition to these temporary mobiles sensors, fixed sensors; which are attached to a particular structural location permanently and measure a group of subjects and their environmental status; are also needed. These fixed sensors allow us to collect environmental data in a single space and measure group health status within the space simultaneously. To utilize fixed sensors, a wireless communication standard of a fixed IoT should be primarily considered. In this study, we utilize a Zigbee communication method.

To record real-time information through the measurement of fixed sensor data, an application of BIM (Building Information Modelling) technology that integrates and manages building's structural and usage information is essential. BIM adopts IFC (Industry Foundation Classes) whose main role is an information exchange. IFC standard was developed to express a variety of real-time data in the general construction field of buildings, and to show real-time data during the life cycle of the building (Choo, 2010). 
By integrating all of the suggested technologies and standards, we suggest a framework that can measure and assess QoL of elderly people objectively, by measuring their active aging status through biomarker sensors under a fixed IoT and BIM technology environment.

\section{LITERATURE REVIEW}

We examined the existing literature related to such keywords as QoL, active aging, biomarkers, fixed IoT and BIM. We have noted a combined study on IoT and BIM, whose authors proposed a design process using a symbiotic interaction model between a smart analog model and a digital model to realize a smart architectural space design (Kim and Kim, 2014). Another study introduced how an IoT and active-aging combination, could present a cross platform communication (Konstantinidis, et al., 2015). These authors illustrated that web based IoT platform with a disease management tool, could provide a feasible vehicles for a combined infrastructure system. Yet, efforts like ours study to integrate QoL, biomarkers, and BIM remain as a very novel approach.

\subsection{Definition and Indices of QoL}

Discussions of problems related to quality of life (QoL) have been recorded in USA since the 1960s, while academic efforts regarding QoL problems began in Korea in the mid-1970s, becoming truly active in the 1980s (Kwen, 2008). According to WHO, QoL was defined as an individuals' perception of their position in life in the context of the culture and value systems in which they live and in relation to their goals, expectations, standards and concerns (WHO, 1998). ISOQOL (International Society for Quality of Life Research) defined HealthRelated Quality of Life (HRQOL) as follows: "There is broad agreement that HRQOL is the functional effect of a medical condition and/or its consequent therapy upon a patient". And the CDC (Centers for Disease Control and Prevention) has defined HRQOL as "an individual's or group's perceived physical and mental health over time" (CDC, 2000).

Types of scales used in existing studies to evaluate QoL varied widely, while sharing common indices reflecting physical and mental aspects. Table 1 displays the QoL scales that have been used.

Table 1 - QoL Index in Existing Studies

\begin{tabular}{|l|l|l|l|}
\hline \multicolumn{1}{|c|}{ Title } & \multicolumn{1}{|c|}{$\begin{array}{c}\text { Author } \\
\text { (year) }\end{array}$} & QoL index & \multicolumn{1}{c|}{ Details } \\
\hline $\begin{array}{l}\text { Centers for Disease Control } \\
\text { and Prevention. Measuring } \\
\text { healthy days: Population } \\
\text { assessment of health-related } \\
\text { quality of life }\end{array}$ & CDC (2000) & HRQOL & $\begin{array}{l}\text { recent pain, depression, } \\
\text { anxiety, sleeplessness, } \\
\text { vitality, current activity } \\
\text { limitation }\end{array}$ \\
\hline
\end{tabular}




\begin{tabular}{|c|c|c|c|}
\hline Title & $\begin{array}{c}\text { Author } \\
\text { (year) }\end{array}$ & QoL index & Details \\
\hline $\begin{array}{l}\text { Measuring QoL with SF-36 in } \\
\text { Older Americans with TBI }\end{array}$ & $\begin{array}{l}\text { Yang, et al. } \\
(2012)\end{array}$ & SF-36 & $\begin{array}{l}\text { general health, physical } \\
\text { function, role-physical } \\
\text { function, body pain, } \\
\text { vitality, social function, } \\
\text { role-emotional function, } \\
\text { mental health }\end{array}$ \\
\hline $\begin{array}{l}\text { Effects of a Cognition } \\
\text { Activation Program for the } \\
\text { Institutionalized Old-Old in } \\
\text { Korea }\end{array}$ & $\begin{array}{l}\text { Lee and Lee } \\
(2013)\end{array}$ & WHOQOL & $\begin{array}{l}\text { physical health, } \\
\text { psychological health, } \\
\text { independence, social } \\
\text { relationship, economic } \\
\text { level, life environment } \\
\text { level }\end{array}$ \\
\hline $\begin{array}{l}\text { The psychometric properties of } \\
\text { the German version of the } \\
\text { WHOQOL-OLD in the } \\
\text { German population aged } 60 \\
\text { and older }\end{array}$ & $\begin{array}{l}\text { Conrad, et al. } \\
(2014)\end{array}$ & $\begin{array}{l}\text { WHOQOL- } \\
\text { OLD }\end{array}$ & $\begin{array}{l}\text { sensory activities, } \\
\text { autonomy, past \& present } \\
\text { and future activities, } \\
\text { participation, death and } \\
\text { dying, intimacy }\end{array}$ \\
\hline $\begin{array}{l}\text { The Effects of Mental Health } \\
\text { on the Quality of Life After } \\
\text { Stroke }\end{array}$ & $\begin{array}{l}\text { Kim and Shim } \\
(2015)\end{array}$ & SS-QOL & $\begin{array}{l}\text { energy, family role, } \\
\text { language usage, } \\
\text { movement, mood, } \\
\text { individual personality, } \\
\text { self-help activity, social } \\
\text { role, thinking skill, sight, } \\
\text { work-production activity }\end{array}$ \\
\hline $\begin{array}{l}\text { The effect of the multi } \\
\text { intervention program applying } \\
\text { to dementia elderly }\end{array}$ & Kim, et al. (2015) & GQOL-D & $\begin{array}{l}\text { physical, psychological } \\
\text { health, independence level, } \\
\text { social relationship, } \\
\text { environment, religion }\end{array}$ \\
\hline $\begin{array}{l}\text { Dimensions and correlates of } \\
\text { quality of life according to } \\
\text { frailty status: a cross-sectional } \\
\text { study on community-dwelling } \\
\text { older adults referred to an } \\
\text { outpatient geriatric service in } \\
\text { Italy }\end{array}$ & $\begin{array}{l}\text { Bilotta, et al. } \\
(2010)\end{array}$ & OPQOL & $\begin{array}{l}\text { life overall, health, social } \\
\text { relationships and } \\
\text { participation, } \\
\text { independence, control over } \\
\text { life, freedom, home and } \\
\text { neighbourhood, financial } \\
\text { circumstances, } \\
\text { psychological and } \\
\text { emotional wellbeing, } \\
\text { leisure, activities and } \\
\text { religion }\end{array}$ \\
\hline $\begin{array}{l}\text { Comparison of QoL-AD and } \\
\text { DQoL in elderly with } \\
\text { Alzheimer's disease }\end{array}$ & $\begin{array}{l}\text { Wolak-Thierry, } \\
\text { et al. } \\
(2015)\end{array}$ & QOL-AD & $\begin{array}{l}\text { interpersonal relationships, } \\
\text { financial difficulties, } \\
\text { physical condition, } \\
\text { memory, mood, overall } \\
\text { health }\end{array}$ \\
\hline
\end{tabular}




\subsection{Establishing Linkage between QOL Health Problem and Active Aging Bio-markers}

The United States Centers for Diseases Control and Prevention (CDC) presents HRQOL as consisting of 3 modules: healthy days core module, activity limitations module, and healthy days symptoms module. Within the activity limitations module, 14 major health problems are indicated. In parallel, 18 active aging biomarkers are used for elderly people. Most of the biomarkers are applied to such body fluids as blood and urine. The linkage between 5 health problems and the active aging bio-markers are given in Tab. 2 .

Table 2 - Linkage between HRQOL's Health Problem and Active Aging Bio-markers (Quantified Health, 2015)

\begin{tabular}{|c|c|c|}
\hline $\begin{array}{c}\text { Bio } \\
\text { marker }\end{array}$ & Active aging bio-marker & Health problems \\
\hline b1 & Glycated hemoglobin level (HbA1C) (blood sugar) & h11 diabetes \\
\hline b2 & Cardiorespiratory Fitness (estimate of VO2 max) & h8 heart \\
\hline b3 & $\begin{array}{l}\text { Anthropometry } \\
\text { (body measurements e.g. BMI, waist-hip ratio) }\end{array}$ & \\
\hline b4 & Lung function & h5 lung \\
\hline b5 & Blood pressure & h10 hypertension \\
\hline b6 & Leukocyte telomere length & \\
\hline b7 & Creatinine clearance & \\
\hline b8 & Urea nitrogen & \\
\hline b9 & Lipoprotein (a) & \\
\hline b10 & $\begin{array}{l}\text { Non-fasting Triglycerides, Total cholesterol, and } \\
\text { High-density lipoprotein (HDL) cholesterol }\end{array}$ & h9 stroke \\
\hline b11 & Gum health (combined attachment loss) & \\
\hline b12 & White blood cell count & \\
\hline b13 & $\begin{array}{l}\text { C-reactive protein (hsCRP) } \\
\text { (measure of inflammation) }\end{array}$ & \\
\hline b14 & Apolipoprotein A1 & \\
\hline b15 & Apolipoprotein B100 & \\
\hline b16 & Albumin & \\
\hline b17 & Alkaline phosphatase & \\
\hline b18 & $\begin{array}{l}\text { Cytomegalovirus Optical Density } \\
\text { (presence of antibodies against CMV)) }\end{array}$ & \\
\hline
\end{tabular}


Fig. 1 illustrates the average biomarker value changes over 12 year period (Belsky, et al., 2015).

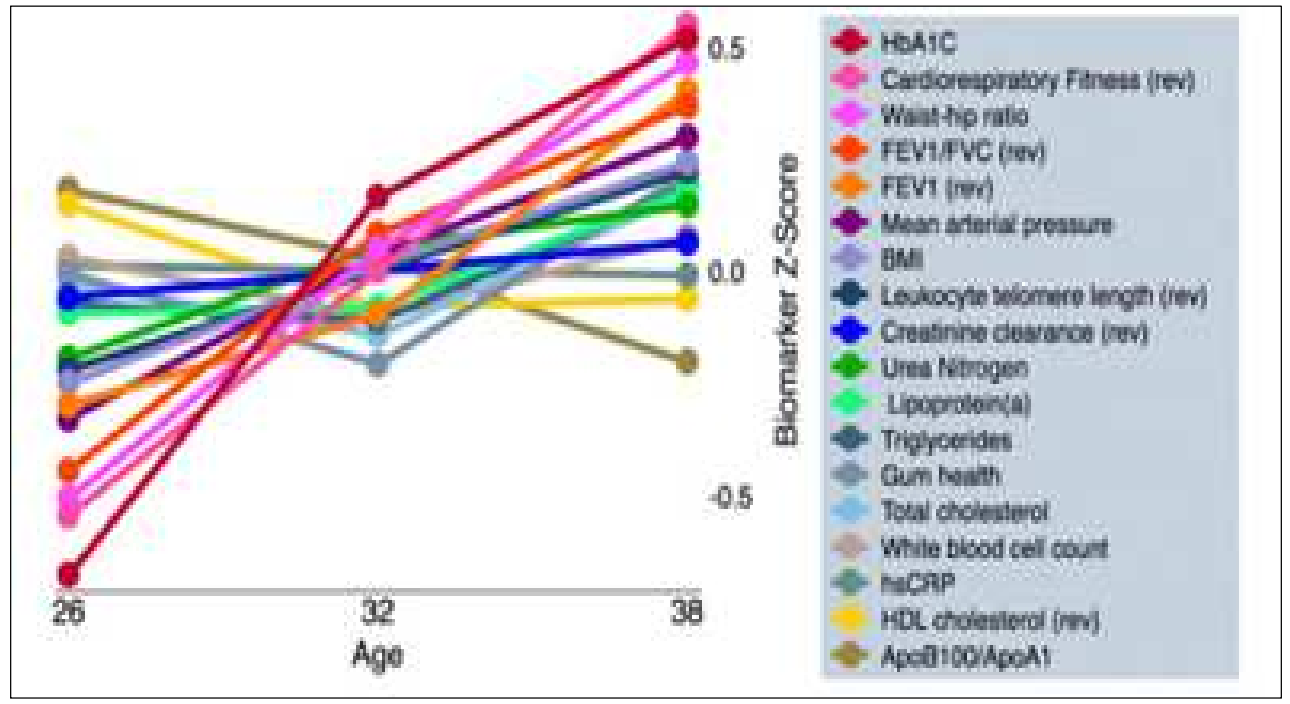

Figure 1 - Changes in Bio-markers during Aging

Other physical health problems including $\mathrm{h} 1$ arthritis, $\mathrm{h} 2$ back/neck problems, $\mathrm{h} 3$ fractures, and $\mathrm{h} 4$ walking problems can be measured by checking Bone Mineral Density (MBD), and Electro-physical tests such as EMG (Electro Myo Gram). Mental health problems are identified through electroencephalogram (EEG). Ultrasound, computed tomography (CT) and magnetic resonance imaging (MRI) scans are used for identifying both musculoskeletal health problems and structural abnormalities in the brain. Table 3 illustrates another set of biomarkers.

Table 3 - Other bio-markers and related health problems

\begin{tabular}{|c|c|c|c|c|c|}
\hline Classification & $\begin{array}{c}\text { Health } \\
\text { problems }\end{array}$ & $\begin{array}{c}\text { Bio- } \\
\text { markers }\end{array}$ & $\begin{array}{c}\text { Measurement } \\
\text { object }\end{array}$ & $\begin{array}{l}\text { Inspection } \\
\text { method }\end{array}$ & Normal range \\
\hline heart & $\mathrm{h} 8$ & b2 & ECG/EKG & current test & $\begin{array}{l}60 \sim 100 \text { heartbeat per } \\
\text { minute }\end{array}$ \\
\hline lung & h5 & b4 & lung capacity & breath test & $\begin{array}{l}\text { male: } 3,500 \mathrm{ml} \\
\text { female: } 2,500 \mathrm{ml}\end{array}$ \\
\hline muscle & h2 & . & EMG & current test & $\begin{array}{l}\text { balance of muscle } \\
\text { in small waveform }\end{array}$ \\
\hline fat & . & b3 & body fat & current test & $\begin{array}{l}\text { male: } 10 \sim 18 \% \\
\text { female: } 20 \sim 25 \%\end{array}$ \\
\hline bone & h3 & . & bone density & $\begin{array}{l}\text { radiographic } \\
\text { inspection }\end{array}$ & $\begin{array}{c}\mathrm{T} \text { value should be over } \\
-1.0\end{array}$ \\
\hline kidney & . & b7 & $\begin{array}{l}\text { creatinine } \\
\text { level }\end{array}$ & blood test & $\begin{array}{l}\text { male: } 0.6 \sim 1.1 \mathrm{mg} / \mathrm{dL} \\
\text { female: } 0.4 \sim 0.8 \mathrm{mg} / \mathrm{dL}\end{array}$ \\
\hline
\end{tabular}




\subsection{Fixed IoT Environment}

Within the nursing home, a main server connects to several master IoTs in living quarters, restaurants, gardens, gyms and playing areas via hard wired and/or wirelessly connections. In this case, the nursing home becomes a smart building providing a smart built environment (SBE), or a fixed IoT environment. The main server is equipped with a Zigbee communication module so that the server itself can be a master IoT. The server is also connected to the external communication network (Fig. 2).

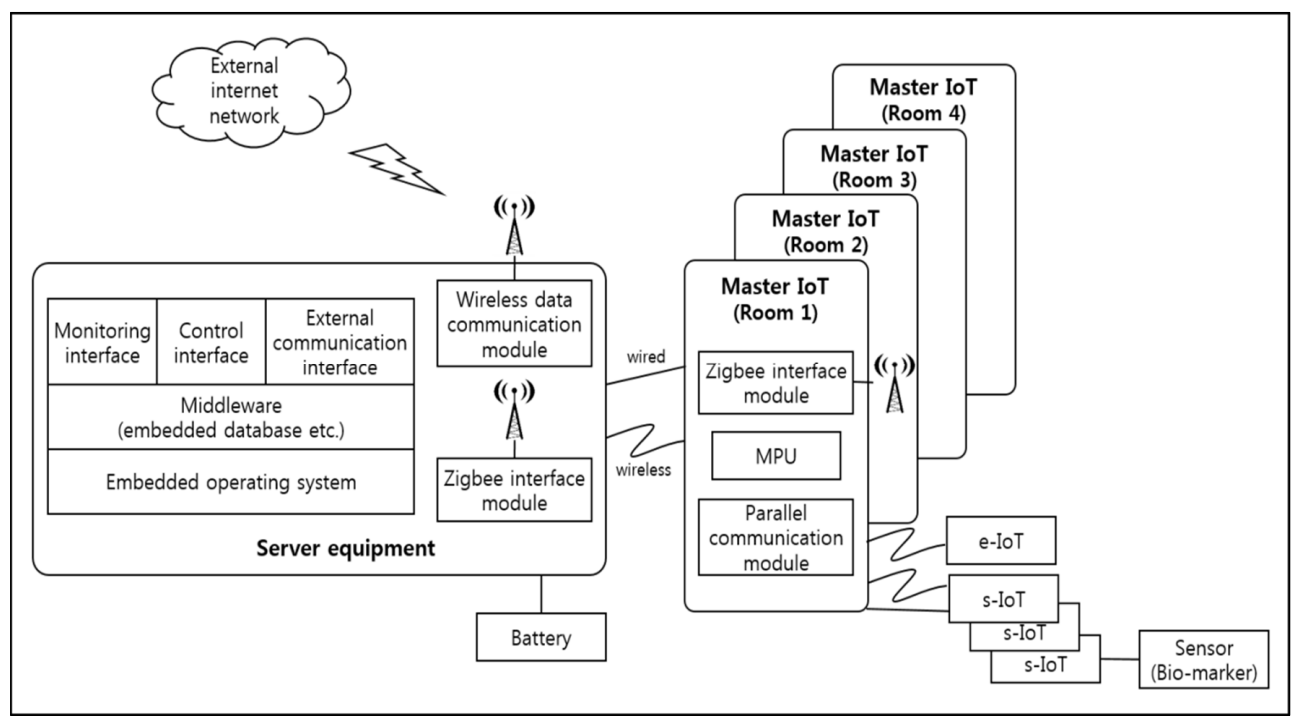

Figure 2 - Fixed IoT environment in a nursing home

A master IoT is assigned to a specific area in a form of fixed IoT. A master IoT collects data from an e-IoT and several s-IoTs through wireless Zigbee communication. An e-IoT is used to identify the subject, in this case an elder resident of the nursing home. One type of s-IoT senses the health status of the elder resident in the nursing home through biomarkers, while the other type of sIoT senses the environmental information of the nursing home (Fig. 3). The typical data transmission rate of Zigbee (IEEE 8002.15.4) is less than 250k bps and has less than 65,500 nodes. The topology of Zigbee could be 1:1, 1:n, or mesh. 


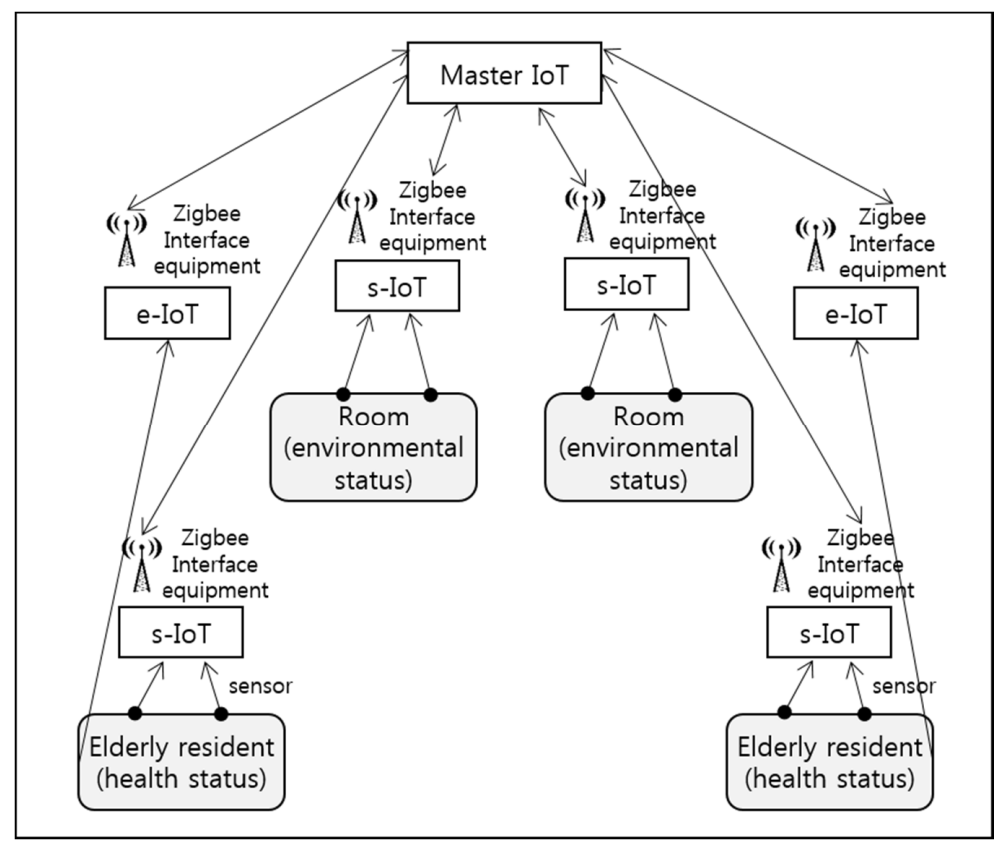

Figure 3 - IoT Communication Method in a Nursing Home

A master IoT use a $447 \mathrm{Mhz}$ RF module (AirBon F400SN), a main MPU (ATxmega256A3BU 8/16 bit), and several RS232 sensor node input ports. Main power is provided by 1 cell lithium-polymer battery $(3.7 \mathrm{~V}, 3150 \mathrm{mAh})$. An MPU provides low power and sends TXD while receiving RXD to and from an RF module, while sending RF/STATUS LED to the server. The data on health status of subject is grouped into a frame (Tab. 4).

\section{Table 4 - Health Status Data Frame}

\begin{tabular}{|c|c|c|c|c|c|c|}
\hline Frame & \multirow{2}{*}{$\begin{array}{c}\text { e-IOT } \\
\text { (from) }\end{array}$} & Time stamp & \multicolumn{4}{|c|}{ Sensor data (s-IOT) Z value } \\
\cline { 3 - 6 } & & $\begin{array}{c}\text { Systolic blood } \\
\text { pressure }\end{array}$ & $\begin{array}{c}\text { Diastolic blood } \\
\text { pressure }\end{array}$ & $\begin{array}{c}\text { Blood sugar } \\
\text { level }\end{array}$ & $\ldots$. \\
\hline ^D1MA1 & $\ldots$. & $\ldots$. & $\begin{array}{c}\text { +value: high } \\
\text { 0 : mean } \\
\text {-value: low }\end{array}$ & $\begin{array}{c}\text { +value: high } \\
\text { 0 : mean } \\
\text {-value: low }\end{array}$ & $\ldots$. & $\ldots$ \\
\hline
\end{tabular}

Data transmission protocols for both environmental status and group health status are based on s-IoTs equipped with bio-markers as set up as in Tab. 5. 
Table 5 - Data Transmission Protocol

\begin{tabular}{|c|c|c|c|c|c|c|c|}
\hline \multirow{2}{*}{ Attribute } & \multirow{2}{*}{ NAME } & \multicolumn{3}{|c|}{ TYPE } & \multirow{2}{*}{ LENGTH } & \multirow{2}{*}{ VALUE } & \multirow{2}{*}{ DESCRIPTION } \\
\hline & & S_ID & V_TYPE & V_ID & & & \\
\hline \multirow{2}{*}{$\begin{array}{l}\text { Health } \\
\text { Status }\end{array}$} & \multirow{2}{*}{$\begin{array}{l}\text { Blood } \\
\text { pressure }\end{array}$} & \multirow{2}{*}{$0 \times 01$} & \multirow{2}{*}{$0 \times 00$} & \multirow{2}{*}{ 0x02 } & \multirow{2}{*}{ 0x0004 } & $\begin{array}{l}0 \times 000 \\
00000\end{array}$ & $\begin{array}{c}\text { Max Value: } 220 \\
\text { (Unit: } \mathrm{mm} \mathrm{Hg} \text { ) }\end{array}$ \\
\hline & & & & & & $\begin{array}{l}0 \mathrm{x} 000 \\
00010\end{array}$ & $\begin{array}{l}\text { Min Value: } 60 \\
\text { (Unit: mm Hg) }\end{array}$ \\
\hline \multirow{4}{*}{$\begin{array}{c}\text { Environm } \\
\text { ental } \\
\text { Status }\end{array}$} & \multirow{2}{*}{ Temperature } & \multirow{2}{*}{$0 \times 91$} & \multirow{2}{*}{ 0x00 } & \multirow{2}{*}{ 0x04 } & \multirow{2}{*}{ 0x0004 } & $\begin{array}{l}0 \mathrm{x} 000 \\
0 \mathrm{BC} 0\end{array}$ & $\begin{array}{c}\text { Min Value: - } \\
60.00 \text { (Unit: }{ }^{\circ} \mathrm{C} \text { ) }\end{array}$ \\
\hline & & & & & & $\begin{array}{l}0 \mathrm{x} 000 \\
05 \mathrm{~A} 00\end{array}$ & $\begin{array}{c}\text { Max Value: } \\
90.00 \text { (Unit: }{ }^{\circ} \mathrm{C} \text { ) }\end{array}$ \\
\hline & \multirow[b]{2}{*}{ Humidity } & \multirow[b]{2}{*}{$0 \times 92$} & \multirow[b]{2}{*}{ 0x00 } & \multirow[b]{2}{*}{$0 \times 06$} & \multirow[b]{2}{*}{ 0x0004 } & $\begin{array}{l}0 \times 000 \\
00000\end{array}$ & $\begin{array}{c}\text { Min Value: } \\
00.00 \text { (Unit:\%) }\end{array}$ \\
\hline & & & & & & $\begin{array}{l}0 x 000 \\
06400\end{array}$ & $\begin{array}{c}\text { Max Value: } \\
100.00 \text { (Unit:\%) } \\
\text { (Weekly) }\end{array}$ \\
\hline
\end{tabular}

\subsection{BIM (Building Information Modeling) and SBE (Smart Building Environment)}

In a smart nursing home building, the residents are referred to the 'building occupants', whose personal safety, comfort and health status are of concern. To reflect such information, a variety of smart objects will be ubiquitously and transparently installed in the Smart Built Environment (SBE) to perform actions, such as sensing and control (Zhang, Seet and Lie, 2015). Especially sensors are installed according to the range space or the effective sensing space area. The range space of a sensor is represented by a range radius and range angle. Storing such information refers to Industry Foundation Classes (IFC) Building Information Modeling (Fig. 4).

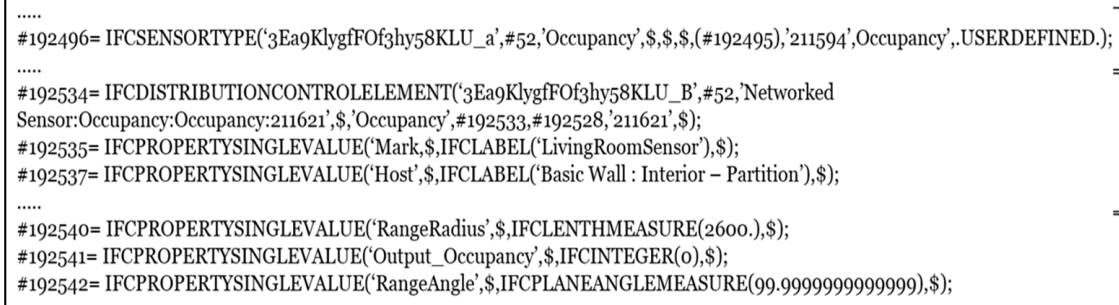

Figure 4 - Code Segment of the Building Information Modelling IFC File for $\mathrm{s}$-IOT

SBE serves to enhance the building's efficiency, security, and comfort of its human occupants by being aware of the state of the environment and performing 
autonomous intelligent actions. Such actions performed by the SBE can be viewed as provisioning a type of service to occupants. These intelligent actions will be dealt with in future studies in a form of either immediate feedback or long term recommendation plans.

The IFC (Industry Foundation Classes) data model is the international standard open file format for BIM. It compiles a variety of information in an overall construction within a schematic structure. IFC schema includes the information structure between space structure foundations that form spaces. Also, the key data of IFC schema mainly consist of IFC Kernel, IFC Control Extension, IFC Process Extension, and IFC Product Extension. Tab. 6 displays the typical specific elements that are included in the IFC schema.

Table 6 - Detail Elements of IFC Schema

\begin{tabular}{|l|l|l|}
\hline IFC schema & Detail element & Examples \\
\hline IFC Kernel & Controls, Instruments & $\begin{array}{l}\text { sensor, actuator, controller, gauge, } \\
\text { meter }\end{array}$ \\
\hline $\begin{array}{l}\text { IFC Product } \\
\text { Extension }\end{array}$ & Environmental Impact & embodied energy, $\mathrm{CO}_{2}$ \\
\hline IFC Kernel & Actors & people, addresses, organizations \\
\hline
\end{tabular}

For environmental factor values for indoor environments; which are needed for the environment setting of fixed IoT; factors suggested in the environmental impact indicators of 'IFC4' can be utilized. Among the 16 factors therein, factors such as Climate Change per Unit or Atmospheric Acidification per Unit can be set as the environmental factor values (Tab. 7).

Table 7 - Factors of Indoor Environmental Elements

\begin{tabular}{|l|l|}
\hline Environmental element & Measuring value \\
\hline Climate Change Per Unit & $\begin{array}{l}\text { Quantity of greenhouse gases emitted calculated in } \\
\text { equivalent } \mathrm{CO}_{2}\end{array}$ \\
\hline $\begin{array}{l}\text { Atmospheric Acidification Per } \\
\text { Unit }\end{array}$ & $\begin{array}{l}\text { Quantity of gases responsible for the atmospheric } \\
\text { acidification calculated in equivalent } \mathrm{SO}_{2}\end{array}$ \\
\hline
\end{tabular}

\section{RESEARCH PLAN}

\subsection{Framework}

In this study, we suggest an objective QoL measurement \& assessment framework that can replace previous subjective QoL measurements. The proposed framework is subdivided into 5 parts: HRQOL, Active-aging \& Biomarkers, Fixed IoT \& BIM/IFC, Derive active-aging \& HRQOL index, and 
Establish linkage HRQOL questionnaire \& active-aging index. Fig. 5 illustrates the proposed framework.

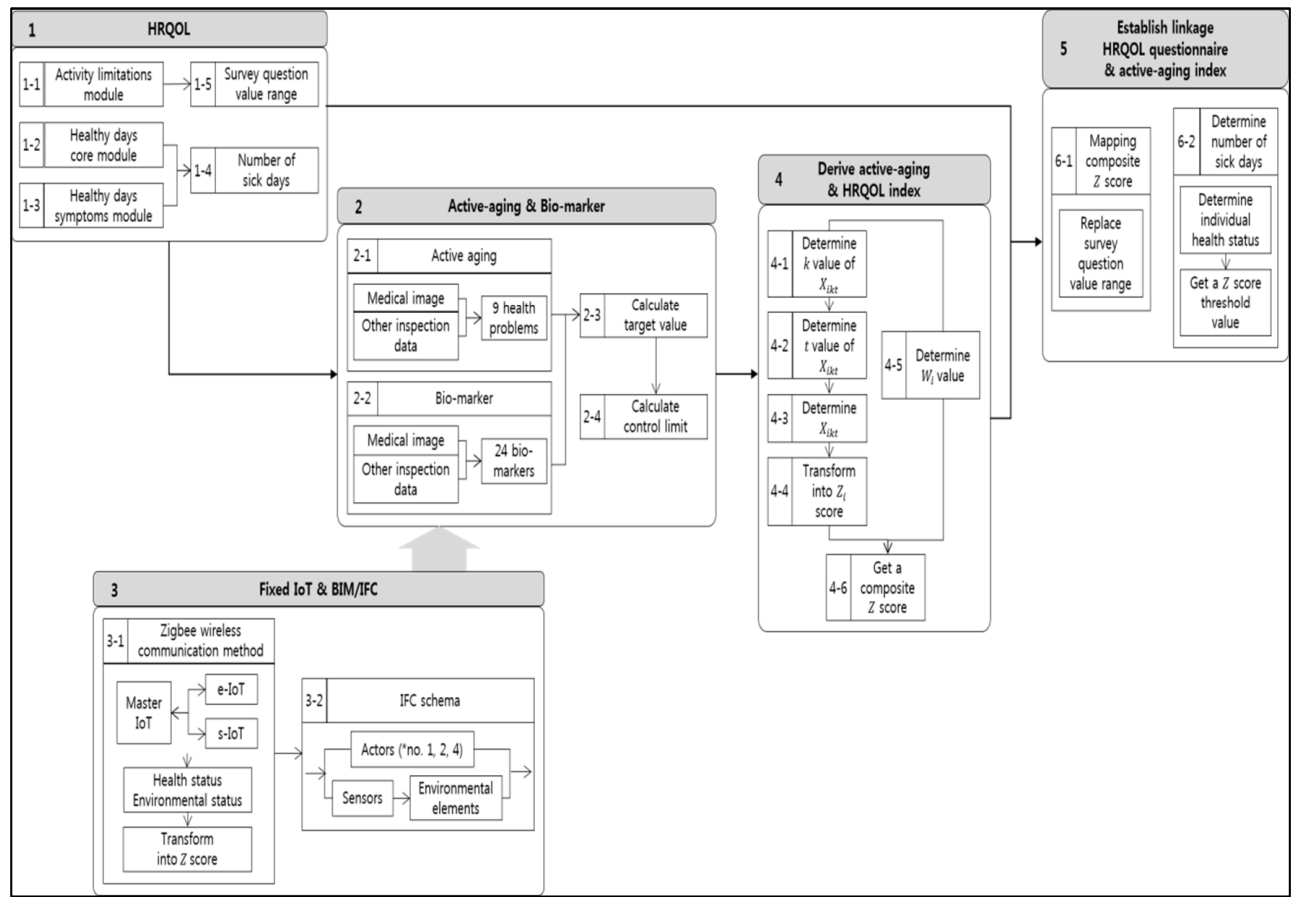

Figure 5 - Proposed Research Framework

\subsection{HR QOL}

The CDC HRQOL is composed of 3 modules: healthy days core module, activity limitations module and healthy days symptoms module. There are two types of questions: one asking whether or not the respondent is under a certain health condition, and the other asking the number of sick days experienced over the past 30 days. For example, the activity limitations module includes a question on whether the respondent's activities are limited or not. Whereas, the healthy days core module covers the question on the number of sick days in the month; the activity limitations module has a question on the duration of activity limited; and healthy days symptoms module covers questions relating to the number of days of having pain, and having not enough rest and sleep.

\subsection{Active-aging \& Bio-marker}

14 major health problems are mentioned in the activity limitations module of HRQOL. Among these, we focus on diabetes, heart problems, lung problems, hypertension, and stroke. In addition, we consider arthritis, back/neck problems, fractures, and walking problems. In active ageing, 18 biomarkers are under consideration. We will also consider ECG/EKG, lung capacity, EMG, body fat, 
bone density, and creatinine levels. Collectively we consider in this study, 9 health problems and 24 biomarkers.

For the 24 biomarker sensor values, we obtained target values and control limits from Clinical Practice Guidelines (CPG).

\subsection{Fixed IoT \& BIM/IFC}

In the Fixed IoT environment, we employ Zigbee wireless communication methods equipped with several master IoTs having e-IoT for subject identification and s-IoT for sensors measuring health status of subjects and environmental factors.

In addition, the information transmitted from 'Sensors'; a sub-item of IFC Kernel; is stored in the form of IFC schema. IFC Kernel stores the information on environmental elements too. Also 'Actors', another sub-item of IFC Kernel, serves to record the information on biomarker values.

\subsection{Derive Active-aging \& HRQOL Index}

Active aging index is a composite weighted $\mathrm{Z}$ score of all bio-markers' $\mathrm{Z}$ score values. To determine the health status of elder people, we consider 24 biomarkers, mostly based on body fluids and medical images (refer to the literature review section). Observed values of bio-marker $X_{i}$ take a form of a data stream, having $k$ consecutive values over a time period from 0 to $t$. We use CUSUM (cumulative sum) of $X_{i k t}$ over $k$ to determine the time ' $t$ ' when CUSUM value reaches a threshold level. After $t$ and $k$ are determined, we transform each biomarker value $X_{i k t}$ into a $Z_{i}$ score. As $99 \%$ of $Z$ score values are in range between -3 and $3, Z^{2}$, the square value of $Z$ score ranges between 0 and 9 . The weight of each $Z$ score is between 1 and 99 where the sum of all the weights is 100. The relative weight of each bio-marker is determined by its representativeness for health status of an elderly person. Although elder people suffer from multiple health problems, the major health problems were chosen for each bio-marker's representativeness (for example, blood pressures represent hypertension). By taking the $200^{\text {th }}$ root of a composite multiplication of all the $Z_{i}$ to the $W_{i}$, we are able to get a composite $Z$ score ranging 0 to 3 .

\subsection{Establish Linkage HRQOL Questionnaire \& Active-aging Index}

Mapping the composite score (whose value ranges between 0 and 3 ) to the value of a HRQOL survey question (whose value ranges between 1 and 4), is simple. However, determining the number of sick days (among the most recent 30 days period that result from a certain health problem), using day by day composite scores is not an easy matter. To overcome this, we would conduct a backward research to get matching HRQOL survey data of elder residents of a nursing home, along with their 30 day composite scores that are obtained from several biomarkers' values for determining active aging health status. By counting the 
composite scores of each resident in descending order, relative to the number of sick days, we could get the composite score threshold value for determining the individual resident's health status in terms of sick days. By collectively distributing obtained threshold values of all the residents, we could get a mean and standard deviation of composite score threshold values for determining the number of sick days resulting from a major health problem. Lastly, we suggest using an algorithm to replace HRQOL survey values into an active-aging index, applying configured materials as before.

\section{PRELIMINARY EMPIRICAL ANALYSIS}

\subsection{Converting Bio-marker Values in a Form of Data Stream into a Single IoT Sensor Value at a Certain Time Point}

Bio-marker values are converted into Z-scores (numbers of standard deviations above or below the mean). The $\mathrm{Z}$ score of a bio-marker $\mathrm{i}$, whose observed value $X_{i k t}$ where $k$ denotes the $k_{t h}$ observation in the data stream at the time $t$, is represented as following:

$$
Z_{i}=\left(X_{i k t}-M_{i}\right) / S_{i}
$$

where $M_{i}$ is a mean value and $S_{i}$ is a standard deviation of bio-marker $i$. To get the single observed value from the data stream, we plan to apply either Mei's algorithm (Mei, 2010) or Tartakovsky's algorithm (Tartakovsky, 2006) to determine the observation point in time $T$.

According to Mei (2010), $T(a)$ is defined as following:

$$
T(a)=\inf \left\{t: \min _{k} \sum_{k=1 . . k} \operatorname{CUSUM}\left(X_{i k t}\right) \geq \text { threshold value } a\right\}
$$

According to Tartakovsky et al. (2006), $T(b)$ is defined as following:

$$
T(b)=\inf \left\{t: \min _{k} \operatorname{CUSUM}\left(X_{i k t}\right) \geq \text { threshold value } b\right\}
$$

Some bio-markers are constantly checking the body status and transmitting the value in seconds whereas the others are generating values in hours. Most of the bio-markers are creating a single data stream while others are generating multiple data streams. For example, blood pressure has the top number (systolic) and the bottom number (diastolic). Mean values of 120 over $80(120 / 80 \mathrm{~mm} \mathrm{Hg})$ are used. We have observed 26 hypertension patients out of 508 subjects during the 
years 2013 and 2015. Their systolic blood pressure ranged between 110 and 220 whereas diastolic blood pressure ranged between 60 and 126 .

\subsection{Deriving HRQOL Composite Index Augmented by Real Time IoT Sensor Values}

The $Z_{i}$ value of the HRQOL index that is based on a single bio-marker is defined by using utility transformation function. $Z_{i}$ is defined as the desirable degree of each test result value. There are 4 types of normality judgement for these check values: 'within specific range', 'larger than specific value', 'smaller than specific value', and 'in specific qualitative value' (Fig. 6).

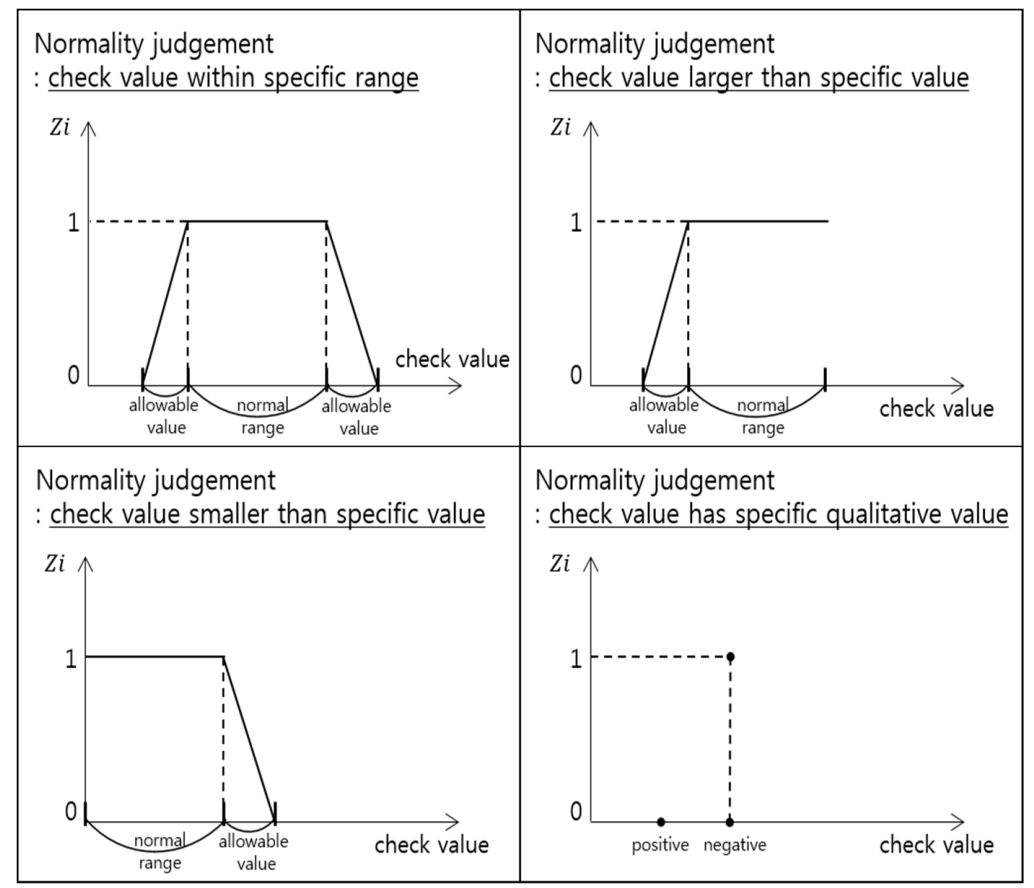

Figure 6-Control Limits of Check Value in Normality Judgement

Also, the formula that calculates the overall HRQOL composite index that decides synthetically the following location of test result values is proposed below.

HRQOL index based on single bio-marker $Z i$.

Overall HRQOL index $=\sqrt[200]{Z_{1}^{2 w 1}} \cdot Z_{2}^{2 w 2} \ldots Z_{k}^{2 w k}, W=w_{1}+w_{2}+\cdots w_{1 k}=100$ 


\subsection{Establishing Linkage between HRQOL Questionnaire and HRQOL Composite Index}

Within the CDC HRQOL 'healthy days core module', a subjective question asking the number of days when physical health was not good (over the previous 30 days) could be replaced with an objective HRQOL composite index.

Within the CDC HRQOL 'activity limitations module', a subjective question on the duration of limited activities due to a specific health problem could be also determined by the objective HRQOL index.

Within the CDC HRQOL 'healthy days symptoms module', a subjective question on the number of days having pain, and another question on number of days having not enough rest and sleep, could likewise be measured by the objective HRQOL index.

For an illustrative purpose, we have observed 30 composite indices of each day's systolic blood pressure level during the recent 30 days (Tab. 8) and obtained HRQOL survey answers indicating the number of days that a typical elderly person suffered from his/her hypertension, (for example, 5 days of limited activities, 10 sick days due to hypertension, 12 days having pain, and 15 days having not enough rest and sleep). From the descending order of data stream of composite indices (Tab. 8), we located the 5th, 10th, 12th, and 15th composite index values of systolic blood pressure level. Using these values as threshold values for determining the number of days suffered for hypertension from other elder people's data streams of composite indices. For example, we add one more day for the number of days 'not having enough rest and sleep' if the subject's composite index of systolic blood pressure level is higher than 0.997890 . Likewise, we add one more day for the number of days of 'limited activities' if the subject's composite index of systolic blood pressure level is higher than 2.757575. Of course, if the systolic blood pressure level is so high, we also add one more day for the number of 'sick days', for the number of 'days having pain', and the number of 'days not having enough rest and sleep'.

Table 8 - The Descending Order of Data Stream of Composite Indices of Each Day's Systolic Blood Pressure Level during Recent 30 Days

\begin{tabular}{|c|c|c|c|}
\hline Day & Composite index value & Day & Composite index value \\
\hline 1 & 3.030303 & 16 & 0.997891 \\
\hline 2 & 3.030303 & 17 & 0.997891 \\
\hline 3 & 2.757576 & 18 & 0.939394 \\
\hline 4 & 2.757576 & 19 & 0.909091 \\
\hline $\mathbf{5}$ & $\mathbf{2 . 7 5 7 5 7 6}$ & 20 & 0.909091 \\
\hline 6 & 2.090909 & 21 & 0.909091 \\
\hline
\end{tabular}




\begin{tabular}{|c|c|c|c|}
\hline Day & Composite index value & Day & Composite index value \\
\hline 7 & 2.090909 & 22 & 0.606061 \\
\hline 8 & 1.939394 & 23 & 0.606061 \\
\hline 9 & 1.666667 & 24 & 0.606061 \\
\hline $\mathbf{1 0}$ & $\mathbf{1 . 3 6 3 6 3 6}$ & 25 & 0.606061 \\
\hline 11 & 1.212121 & 26 & 0.303031 \\
\hline $\mathbf{1 2}$ & $\mathbf{1 . 1 8 1 8 1 8}$ & 27 & 0.110342 \\
\hline 13 & 1.181818 & 28 & 0.110342 \\
\hline 14 & 1.030303 & 29 & 0.110342 \\
\hline $\mathbf{1 5}$ & $\mathbf{0 . 9 9 7 8 9 1}$ & 30 & 0.110342 \\
\hline
\end{tabular}

Within the CDC HRQOL 'activity limitations module', a question on whether activities are limited or not, and questions on "whether or not another person's help is needed for personal care/ needs and routine needs, due to a specific health problems" could be determined from the objective HRQOL index by directly mapping an index value of 0 to the question value of 1 , and mapping an index value of 3 to the question value of 4 .

\section{CONCLUSION}

In this study, we mapped and suggested the active aging measurements and corresponding biomarker sensors that can replace the CDC HRQOL subjective questions value, and configured an environment to objectively measure the previously suggested list using Fixed IoT and BIM/IFC. In this regard, we suggested a framework for obtaining HRQOL questions values from active aging composite indices.

This study is meaningful in that it suggests a method of replacing the conventional QoL survey with objective QoL measurements through IoT sensors. For elder people, in some cases, they cannot reply to the questionnaires accurately/ objectively because of physical conditions. Even in such cases as these, the method suggested in this study enables us to measure and evaluate the QoL of these elder people.

Furthermore, we consider the surrounding environment that might greatly affect the QoL of individuals. Therefore, in this study, we measured the environmental status as well as health status, considering a range of elements to improve the QoL of the subjects in general. 
Additionally, in this study, we configured the network topology to exchange sensor information in an indoor environment using fixed IoT and IFC technology which has not been suggested in any previous studies.

However, in this study, we mainly focused on establishing a relationship between the existing HRQOL survey and active-aging biomarker measurements. Our study focused on deriving a feasible method for augmenting extant subjective HRQOL index by the use of objective, real-time IoT sensor values. Moreover, the research subjects were limited to being individual elderly residents of a nursing home.

We plan to expand the scope of the research to include group level HRQOL in addition to individual level HRQOL. Much of the emotional HRQOL and activity limitations are known to be affected by interactions among neighboring group members. We expect the group HRQOL dynamics will result in upward or downward shifts of individual composite indices.

At this research stage, monitoring trends of composite indices draw our attention. Based on this preliminary result, we plan to devise a feedback mechanism to enable an upward shift of composite indices. In the end, we expect to come up with both individual and small group recommendation practice guidelines for improving HRQOL.

\section{REFERENCES}

Belsky, D.W., Caspi, A., Houts, R., Cohena, H.J., Corcorane, D.L., Danese, A., Harrington, H., Israel, S., Levine, M.E., Schaefer, J.D., Sugden, K., Williams, B., Yashin, A.I., Poulton, R. and Moffitt, T.E., 2015. Quantification of biological aging in young adults. Proceedings of the National Academy of Sciences of the United States of America, 112(30), pp.4104-4110.

Bilotta, C., Bowling, A., Casè, A., Nicolini, P., Mauri, S., Castelli, M. and Vergani, C., 2010. Dimensions and correlates of quality of life according to frailty status: a cross-sectional study on community-dwelling older adults referred to an outpatient geriatric service in Italy. Health and Quality of Life Outcomes, 8, pp.56-66.

CDC (Centers for Disease Control and Prevention), 2000. Measuring Healthy Days: Population Assessment of Health-Related Quality of Life. Georgia: Centers for Disease Control and Prevention.

Choo, S.Y., 2010. IFC \& IFC-based Technology. Review of Architecture and Building Science, 54(1), pp.26-30.

Conrad, I., Matschinger, H., Riedel-Heller, S., Von Gottberg, C. and Kilian, R., 2014. The psychometric properties of the German version of the WHOQOLOLD in the German population aged 60 and older. Health and Quality of Life Outcomes, 12(1), pp.105-117. 
Kim, D. and Kim, S., 2014. A Symbiotic Design Process of Digital - Analog Models and the Role of BIM in the Next Generation Design Environment. Journal of the Architectural Institute of Korea Planning \& Design, 30(11), pp.49-56.

Kim, H., Lee, C., Jung, H., Lee, G. and Kim, D., 2015. The effect of the multi intervention program applying to dementia elderly. The Journal of Korean Society of Community Based Occupational Therapy, 5(2), pp.11-21.

Kim, H. and Shim, M., 2015. The Effects of Mental Health on the Quality of Life after Stroke. Journal of Digital Convergence, 13(2), pp.237-244.

Konstantinidis, E.I., Bamparopoulos, G., Billis, A. and Bamidis, P.D., 2015. Internet of Things For an Age-Friendly Healthcare. Studies In Health Technology And Informatics, 210, pp.587-591.

Kwen, Y., 2008. A Study on Construction and Application of Evaluation Indicators in Quality of Life. Daegu University.

Lee, H. and Lee, D., 2013. Effects of a Cognition Activation Program for the Institutionalized Old-Old in Korea. Journal of Korean community nursing, 24(4), pp.427-437.

Mei, Y., 2010. Efficient scalable schemes for monitoring a large number of data streams. Biometrika, 97(2), pp.419-433.

Quantified Health, 2015. What is your biological age?. [online] Available at: $<$ http://quantifiedhealth.blogspot.sk/2015/08/what-is-your-biological-age.html>.

Tartakovsky, A.G., Rozovskii, B.L., Blažek, R.B. and Kim, H., 2006. Detection of intrusions in information systems by sequential change-point methods. Statistical Methodology, 3(3), pp.252-340.

WHO, 2002. Active Ageing: A Policy Framework. [online] WHO. Available at: http://www.who.int/ageing/publications/active_ageing/en/ [May 2015].

WHO, 1998. The World Health Organization Quality of Life assessment (WHOQOL): Development and general psychometric qualities. Social Science and Medicine, 46(12), pp.1569-1585.

Wolak-Thierry, A., Novella, J.L., Barbe, C., Morrone, I., Mahmoudi, R. and Jolly, D., 2015. Comparison of QoL-AD and DQoL in elderly with Alzheimer's disease. Aging and Mental Health, 19(3), pp.274-278.

Yang, C., Selassie, A.W., Carter, R.E. and Tilley, B.C., 2012. Measuring QoL with SF-36 in Older Americans with TBI. Applied Research in Quality of Life. 7(1), pp.63-81.

Zhang, J., Seet, B. and Lie, T., 2015. Building Information Modeling for Smart Built Environments. Buildings, 5(1), pp.100-115. 


\section{ABOUT AUTHORS}

Eul Hee Roh, Ph. D candidate - is Student at the Department of Healthcare Management, School of Management, Kyung Hee University, Korea, e-mail: eulhee724@khu.ac.kr.

Sang Chan Park, PhD. - is Professor and Chairperson at the Department of Healthcare Management, School of Management, Kyung Hee University, Korea. His main research areas are Healthcare IT, IoT, Bigdata analytics, Digital hospitals, Quality management, Railway rolling stocks, and Logostics, e-mail: sangchanpark@daum.net.

(C) 2017 by the authors. Submitted for possible open access publication under the terms and conditions of the Creative Commons Attribution (CC-BY) license (http://creativecommons.org/licenses/by/4.0/). 